\title{
MANIFESTAÇÕES PATOLÓGICAS EM VIGAS T OU I DE CONCRETO ARMADO DAS OBRAS DE ARTE ESPECIAIS LOCALIZADAS NA BR-020 NO ESTADO DO CEARÁ
}

\author{
SILVA, TALITA E. P. \\ Engenheira Civil \\ DNIT/Engefoto \\ Brasília/DF; Brasil \\ talitaevelyn.te@gmail.com
}

\author{
SILVA, PATRÍCIA C. S. \\ Engenheira Civil, MsC. \\ DNIT/Engefoto/UnB/UNIProjeção \\ Brasília/DF; Brasil \\ patriciacandida@gmail.com
}

\author{
VIERA, JORDANA F. \\ Engenheira Civil \\ DNIT/Engefoto/UnB \\ Brasília/DF; Brasil \\ jordanaferreirav@gmail.com
}

\author{
SARKIS, JORGE M. \\ Engenheiro Civil, MsC. \\ DNIT/Strata Engenharia \\ Brasília/DF; Brasil \\ jorge.sarkis@dnit.gov.br
}

\author{
SOBRINHO, BRUNNO E. \\ Engenheiro Civil, MsC \\ DNIT/Engefoto/UnB \\ Brasília/DF; Brasil \\ brunnosobrinho@engefoto.com.br
}

\author{
CÂMARA, MYRELLE Y. F. \\ Engenheiro Civil, MsC \\ DNIT/Strata Engenharia/UnB \\ Brasília/DF; Brasil \\ myrelleyasmine@hotmail.com
}

\author{
ANHAIA, CÍNTIA A. A. L. \\ Engenheira Civil \\ DNIT/Engefoto \\ Brasília/DF; Brasil \\ cintializ@engefoto.com.br
PINTO JÚNIOR, AYMORÉ V.
Engenheiro Civil
DNIT
Brasília/DF; Brasil
aymore.vaz@dnit.gov.br

\section{RESUMO}

A presença de manifestações patológicas em elementos estruturais das Obras de Arte Especiais (OAEs) apresenta uma preocupação quanto à estabilidade e conservação da obra. Em vista disso, as inspeções em OAEs são essenciais para garantir a segurança do usuário e acompanhar a funcionalidade e durabilidade dos elementos, preferencialmente realizada por inspeções periódicas. Este trabalho tem como objetivo identificar as manifestações patológicas existentes no elemento viga $\mathrm{T}$ ou I de concreto armado das OAEs localizadas na BR-020, no estado do Ceará. Para isso, foi realizado um levantamento quantitativo dos danos existentes no elemento por meio das inspeções realizadas, entre o período de 2018 e 2019, e inseridas no Sistema de Gerenciamento de Obras de Arte Especiais (SGO) do Departamento Nacional de Infraestrutura de Transportes (DNIT). A partir disso, foi possível observar que das 35 obras existentes dessa rodovia, os danos cadastrados no sistema foram o concreto desagregado com armadura exposta e oxidada $(74,29 \%)$ das obras com essa manifestação patológica, armadura sem cobrimento $(45,86 \%)$, infiltração no concreto $(37,14 \%)$, e dentre outros. Assim, concluiu-se que o dano mais recorrente em vigas T ou I de concreto armado das Obras de Arte Especiais na BR020, no estado do Ceará, foi o concreto desagregado com armadura exposta e oxidada. Além disso, 71,43\% das notas técnicas do elemento analisado não influenciaram na nota de estabilidade da obra.

Palavras-chave: Obras de Arte Especiais, Viga T ou I de concreto armado e Manifestações patológicas.

\section{ABSTRACT}

The presence of pathological manifestations in structural elements of the Special Engineering Structures presents a concern regarding the stability and conservation of the bridges. Because of this, bridges inspections are essential to ensure user safety and to monitor the functionality and durability of the elements, preferably performed by periodic inspections. This paper aims to identify the pathological manifestations existing in the reinforced concrete beam element of the bridges located on BR-020, in the state of Ceará. For this, a quantitative survey of the damage existing in the element was carried out through the inspections carried, out between 2018 and 2019, and inserted in the Management System for Special Engineering Structures of the National Department of Transport Infrastructure (DNIT). From this, it was possible to observe the 35 bridges inspections of this highway, the damages registered in the system was disaggregated concrete with exposed and oxidized reinforced (74.29\%) of the bridges with this pathological manifestation, reinforced without covering $(45.86 \%)$ and concrete infiltration (37.14\%), and among others. Thus, it was concluded that the most common damage to 
reinforced concrete T or I beams of the Special Engineering Structures on BR-020, in the state of Ceará, was the disaggregated concrete with exposed and oxidized reinforced. Moreover, 71,43\% of the technical notes of the analyzed element did not interfere with the work's stability score.

Keywords: Special Engineering Structures, Reinforced concrete T or I beam, Pathological manifestations.

\section{INTRODUÇÃO}

As Obras de Arte Especiais (OAEs) têm proporções e características peculiares e contemplam as estruturas como pontes, viadutos, túneis e passarelas. Segundo a Pesquisa CNT de Rodovias (2017), elas são projetadas e construídas para sobrepor barreiras físicas, como cursos d'água, outras vias ou desníveis topográficos , assim garantindo uma rede viária eficiente nos modos de transporte rodoviário, ferroviário e aquaviário. Segundo o Manual de Manutenção de Obras de Arte Especiais (2016), a manutenção dessas obras pode ser definida como o conjunto de atividades que permitem manter a integridade estrutural em um nível adequado de uso. Em vista disso, o acompanhamento da condição de estabilidade e de conservação da OAE é realizado através de inspeções periódicas, sendo analisada a funcionalidade e durabilidade dos elementos da estrutura.

O planejamento e o procedimento das inspeções em OAEs podem ser realizados de diversas maneiras e em períodos distintos. É estabelecido critérios para inspeções em pontes, viadutos, pontilhões e bueiros de concreto armado ou protendido, podendo ser por inspeção cadastral, que é realizada após a conclusão da obra ou na primeira inspeção ou quando a obra é submetida a importantes alterações estruturais; por inspeção rotineira, a cada dois anos; inspeção especial, a cada cinco anos; inspeção extraordinária, quando ocorrer um grave acidente na obra; ou por inspeção intermediária, para certas obras, quando recomendado por inspeções anteriores (DNIT 010 - PRO, 2004).

O Sistema Nacional de Viação (SNV) é um programa que mantém o georreferenciamento da malha rodoviária federal do Departamento Nacional de Infraestrutura de Transportes (DNIT). As OAEs localizadas nessa rede são administradas pela própria autarquia, que possui o Sistema de Gerenciamento de Obras de Arte Especiais (SGO), no qual possui um banco de dados que possibilita a inserção de Inspeções Cadastrais e Rotineiras (InCR) e Inspeções Rotineiras (InR), além de mantê-las. Para o preenchimento deste sistema, o DNIT possui contratos com empresas que realizam as inspeções em campo de forma periódica, avaliações e gerenciamentos das Obras de Arte Especiais. Na avaliação é estabelecida a nota técnica dos elementos da obra mediante a análise dos registros fotográficos que apresentam todos os danos da estrutura, entretanto isso é possível devido aos critérios estabelecidos na norma ABNT NBR 9452 (2019) e na norma DNIT - PRO (2004).

De acordo com a norma ABNT NBR 9452 (2019), os elementos de uma Obra de Arte Especial podem compor a superestrutura, mesoestrutura, infraestrutura, encontros e partes complementares. Conforme Fernandes e Correia (2017), a superestrutura pode ser de madeira, alvenaria (pedras e tijolos), concreto armado, concreto protendido ou aço. Em vista disso, dependendo do tipo de material, pode-se identificar diferentes manifestações patológicas no elemento, pois cada material tem um comportamento diferente do outro, assim, as causas dos danos podem ser diferentes.

Diante disso, no estado do Ceará há uma quantidade considerável de Obras de Arte Especiais nas rodovias federais com diferentes tipos de estruturas. Nesse sentido, esse trabalho tem como objetivo principal analisar, através de inspeções realizadas entre o período de 2018 e 2019, as manifestações patológicas presentes em vigas T ou I de concreto armado das OAEs localizadas na BR-020 no estado do Ceará, sendo esta uma rodovia federal radial do Brasil de grande importância viária.

\section{INSPEÇÕES EM OBRAS DE ARTE ESPECIAIS}

O Departamento Nacional de Infraestrutura de Transportes possui contratos ativos de inspeções em Obras de Arte Especiais com a finalidade da contratação de serviços técnicos especializados para acompanhar as condições de estabilidade e de conservação das pontes, viadutos e pontilhões, e atualizar o banco de dados do Sistema de Gerenciamento de Obras Arte Especiais. Para isso, os editais preveem "Atividades em Campo" e "Atividades em Escritório". As Atividades em Campo são compostas pela realização de Inspeções Cadastrais e Rotineiras (InCR) e Inspeções Rotineiras (InR) em OAEs, executadas por equipes que podem chegar a ter cinco profissionais em cada contrato. Já as Atividades em Escritório são responsáveis pela coordenação e assessoramento do contrato, também chegando a ter cinco profissionais em cada contrato. 
A divisão em termos de Unidades Federativas para a realização das atividades pode ser através de dois lotes, sendo o Lote 01 composto pelos estados de AL, AP, BA, CE, MA, PA, PB, PE, PI, RN, SE e TO, e o Lote 02 por AC, AM, DF, ES, GO, MG, MS, MT, PR, RJ, RO, RR, RS, SC e SP. Assim, a atuação dos profissionais da Atividade em Escritório é de forma cruzada, onde no Lote 01 auxilia nas avaliações e validações dos dados das inspeções de OAEs apresentadas no SGO, que foram realizadas pela equipe da "Atividade em Campo" do Lote 02, e vice-versa para o outro lote. Então, a respeito do estado do Ceará, a equipe do Lote 01 realizou as inspeções de OAEs, por meio das "Atividades em Campo" e a equipe do Lote 02 auxiliou por meio das "Atividades em Escritório" realizando a avaliação e as demais atividades de gerenciamento das inspeções de OAEs.

Em função da quantidade de Obras de Arte Especiais no estado do Ceará, especificamente, na BR-020, que é uma rodovia radial de suma importância para o estado e o país, é essencial a análise da funcionalidade e da durabilidade dos elementos das obras que a compõe. Para isso, é realizada as inspeções e em seguida, as avaliações das OAEs, considerando o estágio dos danos nos elementos, sendo que nesse estudo, especificamente, o foco foi avaliar os danos existentes no elementoviga T ou I de concreto armado existentes na rodovia em questão.

A BR-020 é uma rodovia federal que se situa na capital federal em direção aos extremos do país (Figura 1). Conforme a Pesquisa CNT de Rodovias (2019), essa rodovia corta o Distrito Federal e os estados de Goiás, Bahia, Piauí até chegar no Ceará com uma extensão total de $1.587 \mathrm{~km}$ e, especificamente no Ceará, a Pesquisa CNT de Rodovias (2016) indica que a extensão é de $439 \mathrm{~km}$. Destaca-se que, verificando os dados existentes no Sistema de Gerenciamento de Obras de Arte Especiais (SGO), nesse estado há 11 rodovias federais com 360 OAEs e, exclusivamente, na BR-020/CE há 77 OAEs, ou seja, quase $22 \%$ das OAEs federais do Ceará estão nessa rodovia.

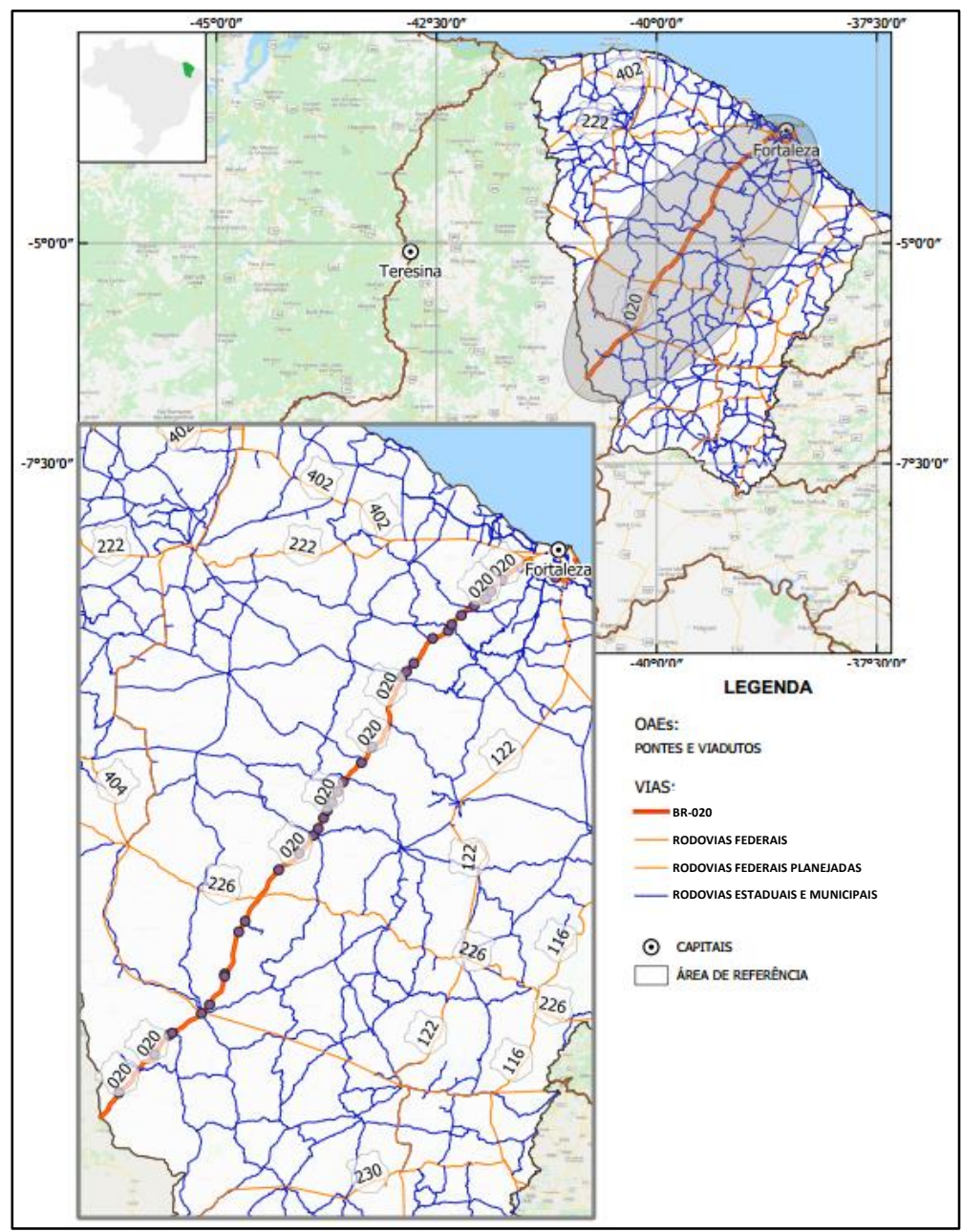

Figura 1: Rodovia BR-020 no estado do Ceará 


\subsection{Sistema de Gerenciamento de Obras de Arte Especiais}

O Sistema de Gerenciamento de Obras de Arte Especiais (SGO) possui 3 divisões de acesso: SGO Mobile, SGO Web, e SGO Inspetor. O SGO Mobile e o SGO Inspetor são acessados pelos inspetores de campo para inserir os dados da inspeção no sistema, e SGO Web é acessado por avaliadores de inspeções, coordenadores e fiscais dos contratos, e demais níveis de acessos possíveis. Com a utilização dessas divisões, o SGO possui informações para complementar a base de dados de OAEs (Figura 2).

\section{Inspeção da OAE}

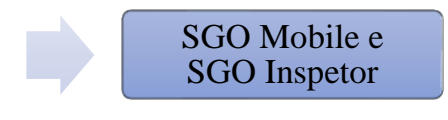

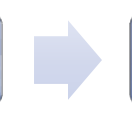

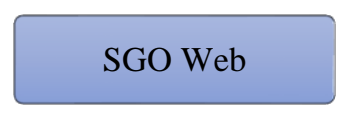

\section{Base de Dados de OAEs}

Figura 2: Fluxos do SGO

Todos os dados das inspeções são registrados no Sistema de Gerenciamento de Obras de Arte Especiais. Dessa maneira, obras com mais de uma inspeção apresentam um histórico no SGO através de relatórios, contendo os dados da Inspeção Cadastral e Rotineira (InCR) e Inspeção Rotineira (InR). Assim, é possível identificar por meio de dados diversos e dos registros fotográficos se há danos e se houve evolução dos danos nas estruturas, as notas técnicas atribuídas aos elementos e por último as notas de conservação e de estabilidade da obra.

\subsection{Metodologia de avaliação das Inspeções de Obras de Arte Especiais}

Para as avaliações das inspeções de Obras de Arte Especiais há uma contextualização através da aplicação de normas e manuais. A análise de cada inspeção em OAEs é baseada, principalmente, na norma ABNT NBR 9452 (2019), que dispõe os requisitos para realização de inspeções em pontes, viadutos e passarelas de concreto e na apresentação dos resultados destas inspeções. Além disso, o DNIT fixa as condições necessárias para a realização de inspeções em OAEs e apresenta o planejamento e o procedimento, informando os diversos tipos de inspeções e as respectivas frequências para a realização dessas verificações, através da Norma DNIT 010 - PRO (2004).

Na avaliação de inspeções de OAEs, cada elemento da obra é analisado e em seguida, é atribuída uma nota técnica a ele, conforme as orientações da Norma DNIT - PRO (2004) e da ABNT NBR 9452 (2019), na qual esta última aborda a situação e os parâmetros apresentados, com as respectivas notas técnicas. Em vista disso, cada OAE possui uma nota técnica, que são as notas de condição de estabilidade e de conservação da obra. A nota da condição de estabilidade é a menor nota atribuída aos elementos estruturais e a nota de condição de conservação é igual a menor nota entre todos os elementos, inclusive os não estruturais (DNIT 010 - PRO, 2004). Diante disso, a norma ABNT NBR 9452 (2019) informa o que abrange cada nota técnica, conforme apresentado na Tabela 1, na qual é possível identificar que as OAEs com a condição de estabilidade excelente apresentam nota técnica 5, já as que são precárias apresentam nota técnica igual a 1.

Tabela 1 - Classificação das notas técnicas da OAE (ABNT NBR 9452, 2019)

\begin{tabular}{|c|c|c|}
\hline $\begin{array}{c}\text { Nota } \\
\text { Técnica }\end{array}$ & $\begin{array}{l}\text { Condição de } \\
\text { estabilidade }\end{array}$ & Classificação das condições da ponte \\
\hline 5 & Boa & Obra sem problemas. \\
\hline 4 & Boa & Obra sem problemas importantes. \\
\hline 3 & $\begin{array}{c}\text { Boa } \\
\text { aparentemente }\end{array}$ & $\begin{array}{l}\text { Obra potencialmente problemática. } \\
\text { Recomenda-se acompanhar a evolução dos problemas através das inspeções rotineiras, } \\
\text { para detectar, em tempo hábil, um eventual agravamento da insuficiência estrutural. }\end{array}$ \\
\hline 2 & Sofrível & $\begin{array}{l}\text { Obra problemática. } \\
\text { Postergar demais a recuperação da obra pode levá-la a um estado crítico, implicando } \\
\text { também sério comprometimento da vida útil da estrutura. Inspeções intermediárias são } \\
\text { recomendáveis para monitorar os problemas. }\end{array}$ \\
\hline 1 & Precária & $\begin{array}{l}\text { Obra crítica. } \\
\text { Em alguns casos, pode configurar uma situação de emergência, podendo a recuperação } \\
\text { da obra ser acompanhada de medidas preventivas especiais, tais como: restrição de } \\
\text { carga na ponte, interdição total ou parcial ao tráfego, escoramentos provisórios, } \\
\text { instrumentação com leituras contínuas de deslocamentos e deformações, etc. }\end{array}$ \\
\hline
\end{tabular}




\subsubsection{Manifestações patológicas}

O Sistema de Gerenciamento de Obras de Arte Especiais apresenta campos de preenchimento pelos usuários para a atribuição de determinados danos para cada elemento. Assim, a nomenclatura dessas manifestações patológicas é padronizada no sistema, evitando o cadastro de um dano com várias identificações divergentes. Especificamente, para o elemento viga $\mathrm{T}$ ou I de concreto armado, em questão, o sistema dispõe de 15 danos, conforme pode ser observado na Tabela 2 a seguir.

Tabela 2 - Danos no elemento viga T ou I de concreto armado apresentados no SGO

\begin{tabular}{|c|c|}
\hline Elemento & Dano \\
\hline \multirow{15}{*}{ Viga $\mathrm{T}$ ou I de concreto armado } & Armadura sem cobrimento \\
\hline & Concreto desagregado com armadura exposta e oxidada \\
\hline & Desplacamento de concreto com armadura exposta \\
\hline & Ferragem principal muito oxidada em pontos localizados \\
\hline & Fissura profunda aberta $(\mathrm{w}>0.3 \mathrm{~mm})$ \\
\hline & Fissura profunda fina \\
\hline & Fissura superficial \\
\hline & Fragmentação por fogo \\
\hline & Infiltração no concreto \\
\hline & Lixiviação e mancha de carbonatação \\
\hline & Mancha de fogo \\
\hline & Mancha de umidade \\
\hline & Nicho de concretagem \\
\hline & Rachadura ou trinca muito aberta \\
\hline & Região com concreto esmagado ou rompido \\
\hline
\end{tabular}

Durante a realização das inspeções, identificou-se por meio de observações nas referidas OAEs que possuíssem a condição "degradação no concreto devido a ação biológica". Essa condição, segundo Anhaia et al. (2019), é um processo de degradação que pode ser por efeito químico, consistindo na redução da vida útil da estrutura através de mudanças na matriz e dos agregados cimentícios. Porém, a referida condição não tem campos de danos para serem cadastrados no SGO, então, conforme sinalizado foi registrado no campo "Observações" das inspeções. Portanto, para esse estudo é abordado somente os danos existentes no sistema (Tabela 2).

Para não haver subjetividades quanto à definição dos danos a serem cadastrados, dispunha-se de documentos com informações dos conceitos de cada dano com os respectivos registros fotográficos de exemplos de determinada OAE. Dessa forma, evita-se cadastramentos errôneos de danos no sistema, sendo que isso pode implicar na definição da nota técnica de estabilidade e de conservação da Obra de Arte Especial. Reitera-se que, antes do início das atividades, as equipes de escritório e de campo foram submetidas a treinamentos a fim de equiparar conhecimentos para a realização de inspeções e avaliações das Obras de Arte Especiais. Dessa maneira, é ratificado os dados registrados pelas equipes, uma vez que as empresas devem apresentar conhecimento profissional suficiente para a realização dessas atividades.

\section{RESULTADOS}

\subsection{Quantificação de danos}

O Sistema de Gerenciamento de Obras de Arte Especiais possibilita apresentar e extrair dados através de filtros de seleção e assim, foi quantificado as obras que possuem o elemento viga T ou I de concreto armado. Dessa maneira, foram 35 OAEs que possuiama superestrutura com esse elemento em questão, localizada na BR-020 no estado do Ceará. A partir disso, a inspeção de cada obra foi analisada para quantificar as manifestações patológicas presentes somente nesse elemento.

No Sistema de Gerenciamento de Obras de Arte Especiais (SGO) existem 15 danos possíveis para serem cadastrados no elemento viga $\mathrm{T}$ ou I de concreto armado, conforme mencionado anteriormente. Na Tabela 3 é possível verificar que as manifestações patológicas principais encontradas nesse elemento foram nove: armadura sem cobrimento, concreto desagregado com armadura exposta e oxidada, fissura profunda aberta (w $>0.3 \mathrm{~mm}$ ), fissura profunda fina, infiltração no concreto, lixiviação e mancha de carbonatação, mancha de fogo, mancha de umidade e nicho de concretagem. Seis 
manifestações patológicas que não foram identificadas, que são o desplacamento de concreto com armadura exposta, ferragem principal muito oxidada em pontos localizados, fissura profunda fina, fragmentação por fogo, rachadura ou trinca muito aberta e região com concreto esmagado ou rompido. Sendo assim, foram identificados um total de 87 danos no elemento viga $\mathrm{T}$ ou I de concreto armado das obras situadas na BR-020/CE.

Tabela 3 - Quantitativo de danos no elemento viga T ou I de concreto armado das OAEs

\begin{tabular}{c|c}
\hline Dano & Quantidades em OAEs \\
\hline Armadura sem cobrimento & 15 \\
\hline Concreto desagregado com armadura exposta e oxidada & 26 \\
\hline Desplacamento de concreto com armadura exposta & 0 \\
\hline Ferragem principal muito oxidada em pontos localizados & 0 \\
\hline Fissura profunda aberta (w > 0.3 mm) & 1 \\
\hline Fissura profunda fina & 1 \\
\hline Fissura superficial & 0 \\
\hline Fragmentação por fogo & 0 \\
\hline Infiltração no concreto & 13 \\
\hline Mixiviação e mancha de carbonatação & 9 \\
\hline Mancha de fogo & 1 \\
\hline Nicho de concretagem & 11 \\
\hline Rachadura ou trinca muito aberta & 10 \\
\hline Região com concreto esmagado ou rompido & 0 \\
\hline
\end{tabular}

Com base na Tabela 3 e na análise da Figura 3, na qual informa o quantitativo e a porcentagem dos danos identificados nas OAEs, respectivamente, a manifestação patológica mais identificada é o concreto desagregado com armadura exposta e oxidada, com $74,29 \%$, seguido do dano armadura sem cobrimento $(42,86 \%)$, infiltração no concreto $(37,14 \%)$, mancha de umidade (31,43\%), nicho de concretagem (28,57\%), lixiviação e mancha de carbonatação $(25,71 \%)$, mancha de fogo $(2,86 \%)$, fissura profunda fina $(2,86 \%)$ e fissura profunda aberta $(\mathrm{w}>0,3 \mathrm{~mm})(2,86 \%)$.

Danos nas Obras de Arte Especiais da BR-020 no estado do Ceará

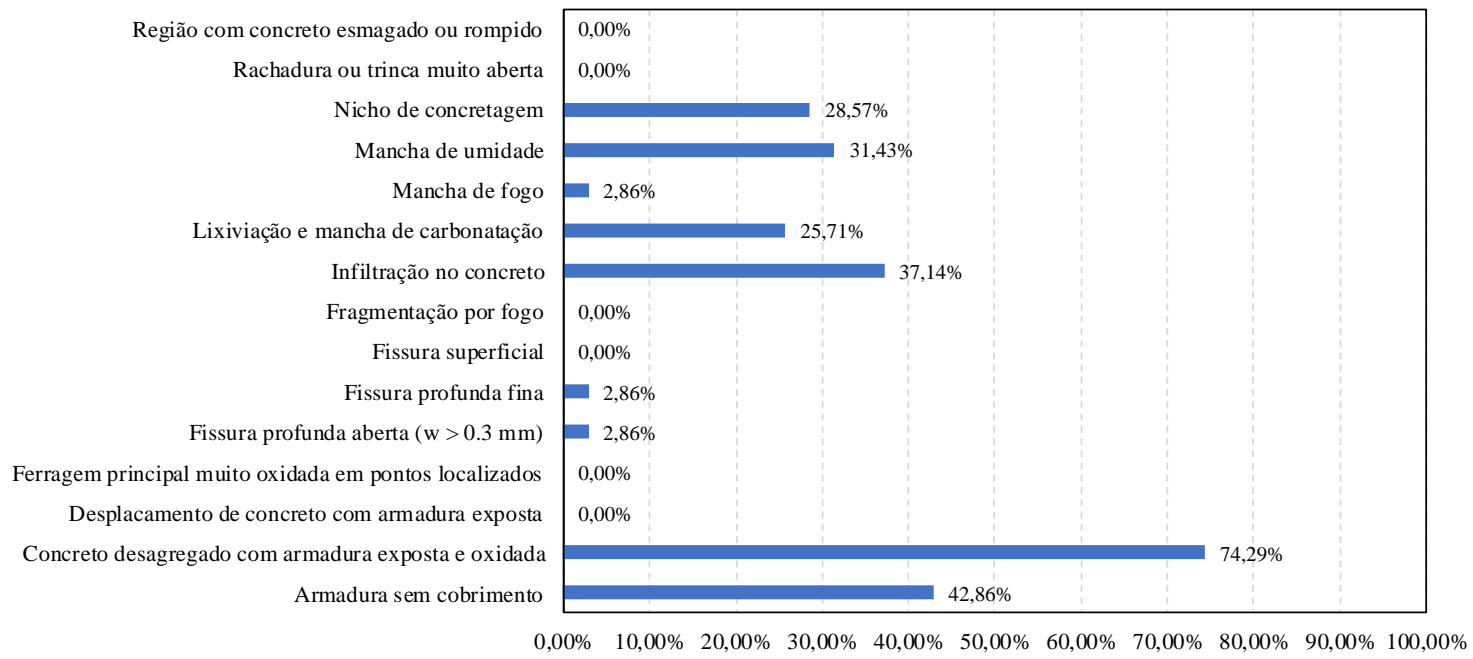

Figura 3: Porcentagem dos danos registrados em vigas T ou I de concreto armado da BR-020 no estado do Ceará

Portanto, o dano mais recorrente nas vigas T ou I de concreto armado, da rodovia federal em questão, é o concreto desagregado com armadura exposta e oxidada (Figura 4). Nesse dano apresenta a desagregação do concreto que, segundo Vasconcelos (2018), é um sintoma da existência de um ataque químico sobre a estrutura e tem como principal característica a perda de coesão entre as partículas que compõem a mistura, ou seja, o concreto é retirado pela ação externa da água, ficando com os agregados livres da união com a pasta, ocorrendo à desintegração da massa de concreto e perda de resistência. Além disso, outra característica desse dano é a identificação da armadura exposta e oxidada no elemento, sendo esse fator definido, pela Norma DNIT 084 - ES (2006), como deterioração do material por ação química ou 
eletroquímica do meio ambiente, alida ou não a esforços mecânicos. Assim, o dano concreto desagregado com armadura exposta e oxidada pode ocasionar a perda de seção dos elementos e até o rompimento das armaduras.

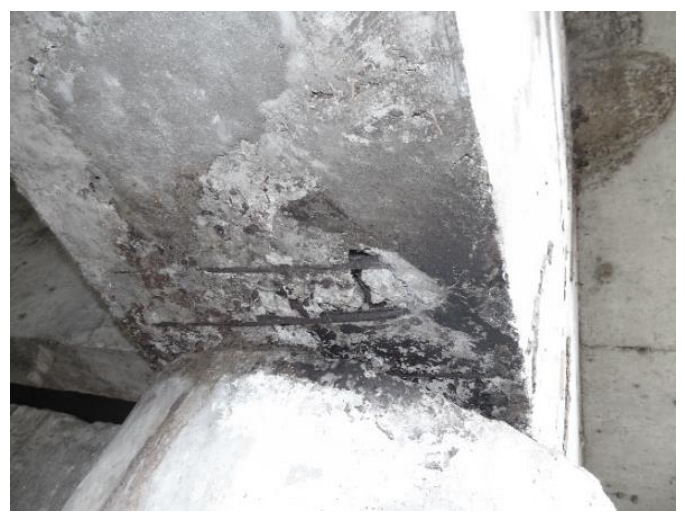

(a)

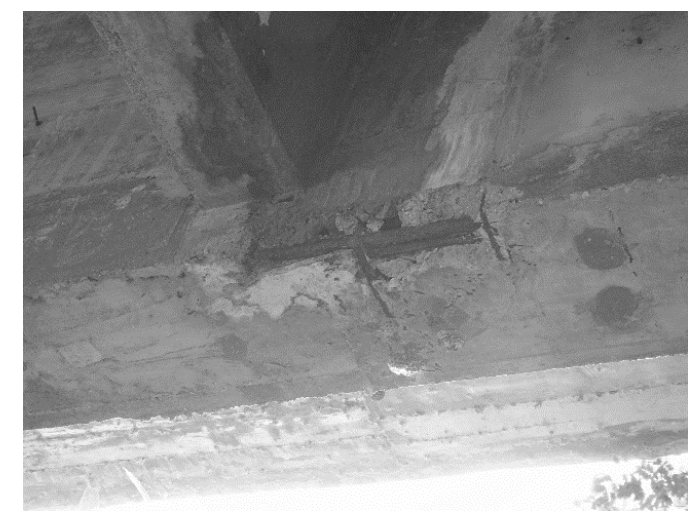

(b)

Figura 4: Concreto desagregado com armadura exposta e oxidada na viga T ou I de concreto armado. (a) Ponte km 230,05 | CE | BR-020 | km 230,05; (b) Ponte sobre o Rio São Gonçalo | CE | BR-020 | 366,02.

\subsection{Interferência da nota técnica da viga}

O elemento viga T ou I de concreto armado inspecionado e avaliado apresenta uma nota técnica, na qual influenciam na nota técnica da condição de estabilidade e de conservação da obra, que são fatores determinantes em outros Programas e Planos do DNIT, como o Programa de Manutenção e Reabilitação de Estruturas (PROARTE) e no Plano Nacional de Manutenção Rodoviária (PNMR). Para saber se a nota técnica da viga T ou I de concreto armado, que é um elemento com função estrutural, influenciou de forma direta para a nota da condição de estabilidade final da obra, levantou-se em consideração as informações de todas as notas técnicas dos elementos viga T ou I de concreto armado das obras, identificando quais obras apresentavam a menor nota técnica dos elementos estruturais da obra influenciada pelo elemento viga T ou I de concreto armado. Com isso, obteve-se os resultados apresentados na Figura 5.

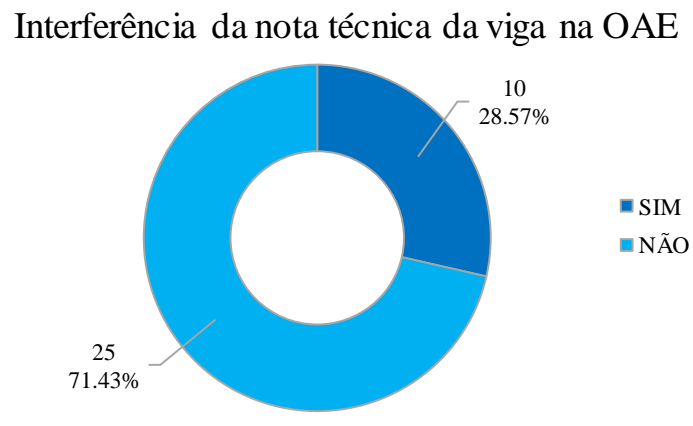

Figura 5: Quantitativo de OAEs com a nota técnica da viga T ou I de concreto armado sendo decisiva para a condição de estabilidade da obra

O Figura 5 apresenta uma divisão de análise entre os termos "SIM" e "NÃO". O termo informado como "SIM" indicam que as OAEs com o elemento viga $\mathrm{T}$ ou I de concreto armado possuiram a menor nota técnica entre os elementos estruturais, resultando em 10 obras, ou seja, $28,57 \%$ do total, e "NÃO" para obras que possuiam outros elementos estruturais com a nota técnica igual ou inferior a do elemento analisado, que foram 25 obras, assim sendo, 71,43\%. Diante disso, é possível afirmar que a maioria das vigas T ou I de concreto armado das Obras de Arte Especiais, localizadas na BR-020 no estado do Ceará, não são decisivas para a condição de estabilidade da obra, ou seja, essa não é a estrutura principal que interfere na atribuição da nota técnica final da obra.

\section{CONSIDERAÇÕES FINAIS}

As Inspeções Cadastrais e Rotineiras (InCR) e as Inspeções Rotineiras (InR), realizadas no período de 2018 e 2019, são preponderantes para a análise de estabilidade e de conservação das obras diante das diversas manifestações patológicas 
que podem surgir nos elementos da Obra de Arte Especial. Dentre os danos presentes na viga T ou I de concreto armado de OAEs, localizadas na BR-020 no estado do Ceará, destaca-se a manifestação patológica de concreto desagregado com armadura exposta e oxidada por ser o mais recorrente, com 74,29\%.

Infere-se, portanto, que há diversos danos nos elementos, os quais têm função estrutural, mas, especificamente, verificouse que a viga $\mathrm{T}$ ou I de concreto armado não apresenta danos suficientes para o elemento ser o fator prejudicial na condição de estabilidade das OAEs analisadas, sendo que em 71,43\% das obras do total, possuiram notas finais influenciadas por manifestações patológicas presentes em outro elemento de função estrutural na obra. Desta maneira, as inspeções e avaliações dos elementos das Obras de Arte Especiais são de suma importância para garantir a segurança do usuário, a funcionalidade e durabilidade da viga $\mathrm{T}$ ou I de concreto armado e de todos os outros elementos da obra.

\section{REFERÊNCIAS}

ANHAIA, C. A. A. L; et al. Degradación debido a la acción biológica de excrementos de murciélagos en las obras de arte especiales en las carreteras de Brasil. Tuxtla Gutiérrez: CONPAT, 2019.

ASSOCIAÇÃO BRASILEIRA DE NORMAS TÉCNICAS. NBR 9452: Inspeção de pontes, viadutos e passarelas de concreto - Procedimento. Rio de Janeiro, 2019.

CONFEDERAÇÃO NACIONAL DO TRANSPORTE - CNT. Pesquisa CNT de rodovias 2016 - Principais dados. Brasília: CNT, SEST, SENAT, 2016. Disponível em: <https://pesquisarodovias.cnt.org.br/Downloads/Galeria\%20de\%20 Fotos/2016/Relatorio\%20por\%20Estado/CE.pdf>. Acesso em: 13 dez. 2019.

CONFEDERAÇÃO NACIONAL DO TRANSPORTE - CNT. Pesquisa CNT de rodovias 2017: Relatório gerencial. Brasília: CNT, SEST, SENAT, 2017. Disponível em: <https://pesquisarodovias.cnt.org.br/edicoes>. Acesso em: 12 dez. 2019.

CONFEDERAÇÃO NACIONAL DO TRANSPORTE - CNT. Pesquisa CNT de rodovias 2019: Relatório gerencial. Brasília: CNT, SEST, SENAT, 2019. Disponível em: <https://pesquisarodovias.cnt.org.br/relatorio-gerencial>. Acesso em: 12 dez. 2019.

DEPARTAMENTO NACIONAL DE INFRAESTRUTURA DE TRANSPORTES. Manual de Manutenção de Obras de Arte Especiais - OAEs. Brasília: Instituto de Pesquisas Rodoviárias, Publicações, 2016, 102 p.

DEPARTAMENTO NACIONAL DE INFRAESTRUTURA DE TRANSPORTES. NORMA DNIT 010/2004 - PRO: Inspeções em pontes e viadutos de concreto armado e protendido - Procedimento. Rio de Janeiro: Instituto de Pesquisas Rodoviárias, 2004.

DEPARTAMENTO NACIONAL DE INFRAESTRUTURA DE TRANSPORTES. NORMA DNIT 084/2006 - ES: Tratamento da corrosão - Especificação de serviço. Rio de Janeiro: Instituto de Pesquisas Rodoviárias, 2006.

FERNANDES, A. V. B.; CORREIA, V. C. Uma introdução ao estudo das pontes em viga. 2017.23 f. TCC (Graduação) - Curso de Engenharia Civil, Ciências Exatas e Tecnológicas, Universidade Tiradentes, Aracaju, 2017.

VASCONCELOS, Flávio de Oliveira. Análise das manifestações patológicas em pontes de concreto armado - estudo de caso. 2018. 69 f. TCC (Graduação) - Curso de Engenharia Civil, Universidade Federal de Alagoas, Delmiro Gouveia, 2018. 